\title{
ON THE TRANSITORY OR ARTIFICIAL FISSURES OF THE HUMAN CEREBRUM.
}

\author{
BY \\ FRANKLIN P. MALL. \\ Professor of Anatomy, Johns Hopkins University. \\ With 1 TABLE.
}

Nearly a century ago J. F. Meckel ${ }^{1}$ discovered the transitory fissures in the cerebrum of human embryos eight or nine weeks old; these he believed to be normal and in no way connected with the permanent fissures. The presence of the transitory fissures was confined by numerous competent anatomists and from time to time their relation to the permanent fissures was discussed. According to Tiedemann they represent the earlier stages of the permanent fissures, and Cunningham states that most of them are obliterated while several "occupy positions which later on are occupied by permanent fissures, and either show direct continuity of existence with these, or at least act as their precursors."

It was gradually shown that the transitory fissures are usually present in embryos of the third and fourth months. To be sure suitable material for study is difficult to obtain and usually the specimens studied were those that had been preserved in alcohol for a considerable time. The influence of alcohol, especially weak alcohol, upon tissues is well known and this naturally led Bischoff in 1868 to suspect that the transitory fissures were artificial, having been produced by the macerating influence of weak alcohol. Furthermore, he found that the fissures were not present in the brains of embryos which had been hardened in chloride of zinc. 'This view is accepted by Marchand (1891) in his paper on the corpus callosum.

Were it not so difficult to obtain fresh human embryos, this question would have been settled long ago. That these fissures are normal seems to be proved by Ecker, in 1869, who observed their presence in the fresh

\footnotetext{
1 References to the literature npon this subject will be found in the following papers: Cunningham, Jour. of Anat. and Phys., XXIV, 1890 ; Hochstetter, Bibliotheca medica, Stuttgart, 1898 ; and Retzius, Biol. Untersuch., X, 1902.
} 
brain of an embryo three months old. Further observation by Hochstetter (1898) shows that they are not present in the fresh brain. Hochstetter examined the brains of two very fresh human embryos and in neither of them was there a trace of a transitory fissure. In other specimens which were well preserved the transitory fissures were only slightly marked, or were not present at all. The observations of Hochstetter are confirmed by Retzius, who had an opportunity to examine the fresh brain of an embryo of the third month. The membranous skull was removed and the specimen hardened in Zenker's solution. After this treatment, it was found that the lateral and mesial surfaces of the brain were perfectly smooth with the exception of a slight depression on the mesial side.

It appears then that when the brains of fresh embryos of the third and fourth months are examined no transitory fissures are found. Furthermore, when fresh specimens are carefully hardened the transitory fissures are insignificant and not numerous, or are not present at all.

About five years ago I noticed that the cerebral vesicles of human embryos hardened in formalin are entirely different from those hardened in alcohol. Not only are the vesicles perfect in form with walls in apposition to the membranes of the skull, but the arrangement of the cells is definite and clear. Specimens hardened in alcohol are sometimes folded and usually macerated, the degree of maceration always being far in excess of that of the rest of the body.

The recent publication of Retzius has induced me to tabulate the condition of the brains in my embryological collection to determine the frequency and degree of transitory fissures in brains hardened in formalin as well as in those hardened in alcohol. The table which I have constructed records the condition of the brains in over fifty specimens. There are about a dozen excellent formalin specimens in the collection not included in the table, for they have not been sectioned and I am unwilling to injure them before they are cut into serial sections. It appears to me that these specimens recorded in the table, together with the observations of Hochstetter and of Retzius, set the transitory fissures aside as artificial products of the effect of weak alcohol upon the brain.

The appended table gives the numbers, the length and the condition of the cerebral vesicles of embryos in my collection in which there are any data relating to the transitory fissures. The specimens have been grouped in months, using for this purpose a rule which has been published recently. ${ }^{2}$ According to this rule the age of an embryo in days

${ }^{2}$ Mall, Johns Hopkins Hospital Bulletin, 1903. 
equals the square root of one hundred times its length from vertex to breech in millimeters. Thus an embryo $30 \mathrm{~mm}$. long is $\sqrt{30 \times 100}$, or 54 days old. Or, to determine the vertex-breech length of an embryo for a given number of days, square the number of days and divide by one hundred. Thus the vertex-breech length of an embryo 30 days old is $\frac{30^{2}}{100}$ or 9 millimeters. The data upon which this rule rests will be found in my paper on the pathology of early human embryos. ${ }^{8}$ This formula applies only to embryos up to $100 \mathrm{~mm}$. in length. In embryos from 100 to $220 \mathrm{~mm}$. long from vertex to breech the length in millimeters equals the age in days.

In nearly all instances the embryos were hardened either in alcohol or in formalin. Not only is this recorded in my notes, but it is also indicated by the condition of the tissue in case the specimen has been cut. It is very apparent from all of my specimens, both normal and pathological, that when the embryo is macerated to the least degree the effect is much more marked in the brain than elsewhere. It appears that any dissociating fluid effects the brain first. So in order to tabulate the specimens I have had to express the extent of maceration of the brain in degrees, which in general is two or three degrees more advanced than that of any other organ of the embryo.

The condition of the brain is marked 0 in the table in case its lateral mesial surfaces are perfectly smooth as pictured by Retzius for the fresh brain of a human embryo at the end of the third month. Those brains in which there are slight irregularities of the walls, as is the case when there is some shrinkage with separation of the vesicle, are marked 1. Some of these folds are certainly not true transitory fissures, for in the same embryos there is the same separation of the epithelial cells in the oesophagus and in the intestine. I have, however, included in this group those brains in which the transitory fissures are just beginning. The brain is marked 2 whenever it has the typical transitory fissures as usually described." In case the infolding is more extended, showing signs of maceration and disintegration of the walls of the brain with loose cells within the ventricle, it is marked 3 . When the maceration has gone so far that the vesicles are filled with cells and the brain is nearly solid, it is marked 4 . In the specimens marked 1 to 4 the spinal

\footnotetext{
${ }^{3}$ Mall, Johns Hopkins Hospital Reports, IX, 1900.

4 The condition of specimens marked 1 equals about those with the least number of fissures as pictured by Retzius on Plate 1 in his great monograph, Das Menschenhirn. Those marked 2 represent those figures on this same plate with the greatest number of fissures.
} 
cord is not macerated very much, but when the entire central nervous system is macerated and solid it is marked 5. So we have, in addition to the embryos in which the surfaces of the brain are smooth, those in which the cerebral vesicles are folded and macerated from the simple small fold up to a stage in which the entire central nervous system is converted into a pulpy mass.

It is seen from the table that the condition of the brain varies very inuch in embryos of the first month as well as in the later months. In four of the embryos the cerebral vesicles are perfect and these are from specimens which were carefully hardened. In the fifth, No. 80, there are no data except that the specimen was hardened in alcohol. One embryo, No. 164, is from an autopsy, and the uterus after it had been cut open was kept on ice for 24 hours before it came into my hands. 'The entire specimen was then placed in strong formalin. Since all of the sections show that the tissues of the body are macerated it is not difficult to understand why the walls of the cerebral vesicles are also macerated and slightly folded.

The embryos of the second month also show a variety of conditions in the cerebral vesicles. There are six perfect ones and three of these were hardened in formalin. One formalin specimen, No. 106, is pretty well macerated, but the specimen had been in water 21 hours before it came into my hands. In it the brain and spinal cord are practically solid.

In No. 86 there is one small fissure on the medial and one on the lateral side of the cerebral hemisphere. This embryo was brought to the laboratory with the amnion unbroken, and without opening it the entire specimen was placed in formalin. It may be that the slight amount of formalin which entered the embryo first acted as a dissociator, caused the cerebral vesicles to expand quicker than the membranes and these narrow transitory fissures followed. In this specimen the fissures are formed by the epithelial wall of the cerebral vesicle turning in without drawing the pia with it. The pia bridges straight over the transitory fissure and the capillaries to the cerebral vesicle are torn off. It is clearly a case of tearing the cerebral vesicle from the pia, which could only have taken place after the death of the embryo.

During the third month it is said that the transitory fissures make their appearance. Among ten specimens there are two with perfect transitory fissures and three with well marked transitory fissures. There are five specimens without any fissures at all and four of them are formalin specimens. One specimen, No. 95, has well-marked total fissures all around the cerebral vesicle. This specimen came to the laboratory fresh and without opening the ovum it was placed in formalin. This 
was the first of the formalin specimens which was eut, and for a long tjme I considered it conclusive proof in favor of the transitory fissures heing normal. Here also the slow penetration of the formalin may have acted more markedly as a dissociator which caused the cerebral vesicles to expand quicker than the membranous walls of the head and thereby produced the slight infolding. In this specimen, as in No. 86, the maceration has caused a scparation of the cerebral walls from the pia over the transitory fissures. At other points the cerebral cells turn outward, forming small microscopic protuberances. In both these specimens the microscopic examination shows clearly that the transitory fissures are produced artificially by the unequal expansion of the cerebral vesicles and the membranous wall. 'The walls of the cerebral vesicles naturally were torn away from the pia along the line of the transitory fissures.

I was fortunate enough to obtain a fresh embryo of the fourth month while tabulating the specimens of my collection. Although the abortion had taken place 21 hours previously, the brain showed no indicitions of fissures at all; in every respect the specimen was like that of Retzius. After the membranous wall had been removed the brain was placed in formalin, in which it retained its smooth form.

'The specimens of the fourth and fifth months are very conclusive. There are nine specimess hardened in formalin and none of them have any transitory fissures. They are present in the four specimens which were hardened in alcohol. A single frosh specimen at the beginning of the fifth month was perfectly sinooth on both mesial and lateral surfaces, although the embryo came into my possession 24 hours after the abortion.

It is apparent from the specimens which have been described that fluids which dissociate tissues are more marked in their effect upon the walls of the cerebral vesicles than upon any of the other tissues of the embryo. Is the cells of the cerebral vesicles become thicker and the tissues firmer the brain substance is more resistant and does not macerate as easily as before, so that by the fifth month transitory fissures can be no longer produced artificially. Formalin, which in strong solutions causes the brain tissue to swell, is a dissociator in very weal solutions, and therefore occasionally produces transitory fissures. According to the experience of Hochstetter, Retzius and myself, the transitory fissures are not found in fresh brains. The transitory fissures are therefore artificial and are of no morphological significance. 


\section{Table of Embryos giving the Condition of the Brain when Hardened in Alcohol or in Formalin.}

0 , indicates that the surface of the brain is smooth; 1 , indicates that there are small folds present; 2 , typical transitory fissures; 3 , folds verg marked with the beginning of maceration; 4, maceration complete and cerebral vesicles nearly solid 5 , entire central nervous system solid.

\section{EMBRYOS OF THE FIRST MONTH.}

\begin{tabular}{|c|c|c|c|c|}
\hline $\begin{array}{l}\text { Number } \\
\text { of } \\
\text { embryo. }\end{array}$ & $\begin{array}{l}\text { V. B. } \\
\text { length of } \\
\text { embryo in } \\
\text { mm. }\end{array}$ & $\begin{array}{c}\text { Condition } \\
\text { of the } \\
\text { brain. }\end{array}$ & $\begin{array}{l}\text { Hardening } \\
\text { fluid. }\end{array}$ & Remarks. \\
\hline 12 & 2 & 0 & Alcohol & $60 \%$ \\
\hline 164 & $31 / 2$ & 1 & Formalin & On ice $24 \mathrm{hrs}$, then in formalin. \\
\hline 148 & $4 \frac{3}{10}$ & 0 & Alcohol & $80 \%$ \\
\hline 76 & $4 \frac{10}{1} / 2$ & 0 & Alcohol & Whole ovum in absolute alcohol. \\
\hline 1 & $41 / 2$ & 5 & & Salicylic acid. \\
\hline 80 & 5 & 0 & Alcohol & \\
\hline 116 & 5 & 2 & Alcohol & \\
\hline 19 & $51 / 2$ & 5 & Alcohol & \\
\hline 2 & $7^{\prime 4}$ & 0 & Alcohol & Ovum in strong alcohol. \\
\hline 4 & 7 & 1 & Alcohol & \\
\hline 18 & 7 & 2 & Alcohol & \\
\hline 113 & 8 & 4 & Alcohol & \\
\hline
\end{tabular}

EMBRYOS OF THE SECOND MONTH.

\begin{tabular}{|c|c|c|c|c|}
\hline 163 & 9 & 0 & Formalin & \\
\hline 88 & 10 & 0 & Alcohol & \\
\hline 114 & .10 & 3 & Alcohol & \\
\hline 109 & 11 & 2 & Alcohol & \\
\hline 175 & 13 & 3 & Alcohol & \\
\hline 144 & 14 & 0 & Formalin & \\
\hline 43 & 16 & 0 & Alcohol & $\begin{array}{l}\text { Embryo within amnion in strong alco- } \\
\text { bol }\end{array}$ \\
\hline 106 & 17 & 5 & Formalin & In water 24 hrs., then in formalin. \\
\hline 9 & $171 / 2$ & 0 & Alcohol & \\
\hline $\mathbf{5}$ & $181 / 2$ & 4 & Aleohol & \\
\hline 74 & 19 & 3 & Alcobol & \\
\hline 22 & 20 & $\mathbf{2}$ & Alcohol & Whole ovum placed in alcohol. \\
\hline 108 & 22 & 4 & Alcohol & \\
\hline 57 & 23 & 5 & Alcohol & \\
\hline 100 & 27 & 5 & Alcohol & Weak alcohol. \\
\hline 45 & 28 & 2 & Alcohol & \\
\hline 86 & 30 & 1 & Formalin & $\begin{array}{l}\text { Embryo within amnion in formalin, } \\
\text { two fissures. }\end{array}$ \\
\hline 75 & 30 & 3 & Alcobol & \\
\hline
\end{tabular}


EMBRYOS OF THE THIRD MONTH.

\begin{tabular}{r|l|l|l|l}
\hline 206 & 40 & 2 & Alcohol & \\
218 & 42 & 0 & & Fresh, 24 hrs. after the abortion. \\
96 & 44 & 0 & Formalin & Whole ovum hardened in formalin. \\
95 & 46 & 1 & Formalin & Whol \\
105 & 48 & 1 & Alcohol & \\
84 & 50 & 0 & Alcohol & \\
169 & 52 & 0 & Formalin & \\
151 & 52 & 1 & Alcohol & Whole uterus with ovum bardened in \\
139 & 55 & 0 & Formalin & Wormalin. \\
& 65 & 2 & Alcohol & Formalin \\
179 & 70 & 0 &
\end{tabular}

EMBRYOS OF THE FOURTH MONTH.

\begin{tabular}{l|r|l|l|}
\hline & 80 & 2 & Alcohol \\
& 90 & 0 & Formalin \\
& 95 & 0 & Formalin \\
100 & 0 & Formalin \\
& 105 & 0 & Formalin \\
& 110 & 0 & Formalin \\
110 & 1 & Alcohol \\
& 112 & 0 & Formalin \\
\hline
\end{tabular}

EMBRYOS OF THE FIFTH MONTH.

\begin{tabular}{r|r|r|l|l}
\hline 219 & 115 & 0 & & Fresh, 24 hrs. after the abortion. \\
149 & 120 & 1 & Alcohol & \\
170 & 125 & 0 & Formalin & \\
48 & 130 & 1 & Alcohol & \\
& 150 & 0 & Formalin & \\
\hline
\end{tabular}

